\title{
Precautionary design of a marine protected area based on a habitat model
}

\author{
Tim Gerrodette*, Tomoharu Eguchi \\ Southwest Fisheries Science Center, NOAA National Marine Fisheries Service, 3333 North Torrey Pines Court, La Jolla, \\ California 92037, USA
}

\begin{abstract}
A basic principle of effective resource management is that decisions should be conservative in the face of uncertainty. Due to limited data, there is often considerable uncertainty about species' habitat relationships and requirements. If the boundaries of a protected area are based on relationships estimated by a habitat model, effective management takes the uncertainty into account. The inclusion of uncertainty in the design of a hypothetical marine protected area is described for a coastal population of the long-beaked common dolphin Delphinus capensis off Baja California, Mexico. Line-transect and depth data were combined in a hierarchical Bayesian model. Two possible management goals were considered: protecting 100000 animals or protecting $60 \%$ of the population. A precautionary approach was adopted, meaning that the management goal should be met with a high probability. The model estimated that a seaward boundary at $360 \mathrm{~m}$ would include 100000 dolphins with a probability of 0.9 . A conventional but less precautionary 'best estimate' boundary at $160 \mathrm{~m}$ would meet the management goal with a probability of 0.5 . For the second goal of including $60 \%$ of the population, the precautionary and non-precautionary depths were 210 and $170 \mathrm{~m}$, respectively. Habitat models are useful for management, but management decisions based on such models should consider the uncertainty inherent in estimating parameters from data. Models which include the data observation process can improve inference about habitat relationships.
\end{abstract}

KEY WORDS: Precautionary management - Marine protected area - Delphinus capensis · Cetacean habitat model $\cdot$ Hierarchical Bayes model

\section{INTRODUCTION}

Cetaceans face a variety of challenges, such as climate change, noise pollution, fisheries bycatch and collisions with ships. For reasons of conservation and management, it is important to understand the habitat requirements of cetaceans, and habitat models play a critical role, as shown by the papers in this special issue. When using the results of habitat models in management decisions, however, it is important to consider the uncertainty inherent in estimating model parameters from data. Insufficient recognition of uncertainty has led to repeated failures in resource management and conservation (Ludwig et al. 1993). The scientific issue is to estimate uncertainty well and to report it in terms that can be clearly understood. The management issue is to recognize that uncertainty exists and to account for it when making decisions.

A basic principle of effective management of natural resources is that decisions should be more conservative when uncertainty is greater (Mangel et al. 1996). For marine mammals, an example of this precautionary principle in practice is the procedure for setting bycatch limits under the US Marine Mammal Protection Act. Bycatch limits are based on the lower end of a confidence interval of an abundance estimate (Wade 1998). Thus, the more uncertainty about marine mammal population size, the larger the confidence interval and the smaller the permitted 
bycatch. Uncertainty is explicitly taken into account for conservative management (Taylor et al. 2000).

Here we apply the precautionary use of uncertainty to the design of a marine protected area, when the design is based on habitat modeling. To be effective for the conservation of a species, the design of a protected area should consider, among other things: (1) how many animals should be protected and (2) where the boundaries of the area should be established in order to protect that number.

In the present paper we deal with the second question. We assume that the first question has already been considered, and that either of 2 potential management targets has been established for a cetacean population: (1) to protect at least 100000 animals or (2) to protect at least $60 \%$ of the population. Maintaining a marine mammal population at $\geq 60 \%$ of carrying capacity is a management goal called the 'optimum sustainable population' level under the US Marine Mammal Protection Act, and is based on the assumed inflection point of a generalized production model of large mammal population dynamics (Gerrodette \& DeMaster 1990). Data to estimate population size and distribution may be limited, and there will often be considerable uncertainty about whether any proposed boundary actually contains 100000 animals or $60 \%$ of the population. A precautionary management approach recognizes the uncertainty, and specifies that the management target be met with reasonably high certainty. What constitutes 'reasonably high certainty' is a policy decision about how precautionary management will be. In the present paper, we assume that the level of certainty has been chosen to be 0.9. Given this policy decision, the scientific problem is to use available data to estimate the location of a boundary which contains 100000 animals with a probability of 0.9 or $60 \%$ of the population size with a probability of 0.9 .

As a case study, we use data on the long-beaked common dolphin Delphinus capensis. This species occurs from southern California to the tip of Baja California off the west coast of North America, including the Gulf of California (Rice 1998). We use the long-beaked common dolphin simply as an illustrative example; we are not suggesting that the species is in danger of extinction or that it requires any more protection than other cetaceans in the area. D. capensis was described as distinct from D. delphis in 1994 (Heyning \& Perrin 1994, Rosel et al. 1994). From the locations of sightings, it is clear that the species occurs primarily in coastal waters. Given the management targets specified above, we need to estimate the location of the offshore boundary of a potential protected area that will meet the management objectives. This requires that we estimate the density of dolphins at a relatively fine spatial scale. Further, we need to convert the uncertainty inherent in the estimation of density into a probability that the true value is included. We use depth as a predictor variable for the habitat model because depth data are readily available on a fine scale, and depth is more likely than distance from shore to be a proxy for the actual processes that the dolphins are responding to, such as food supply.

\section{METHODS}

Line-transect surveys were carried out in the range of Delphinus capensis off the coast of Baja California, Mexico, during 11 yr between 1986 and 2006 (Fig. 1A), as part of larger cetacean surveys in the eastern tropical Pacific Ocean. Beaufort sea state was recorded continuously during each survey. School size and distance from the trackline were recorded for each sighting. Further details on data collection
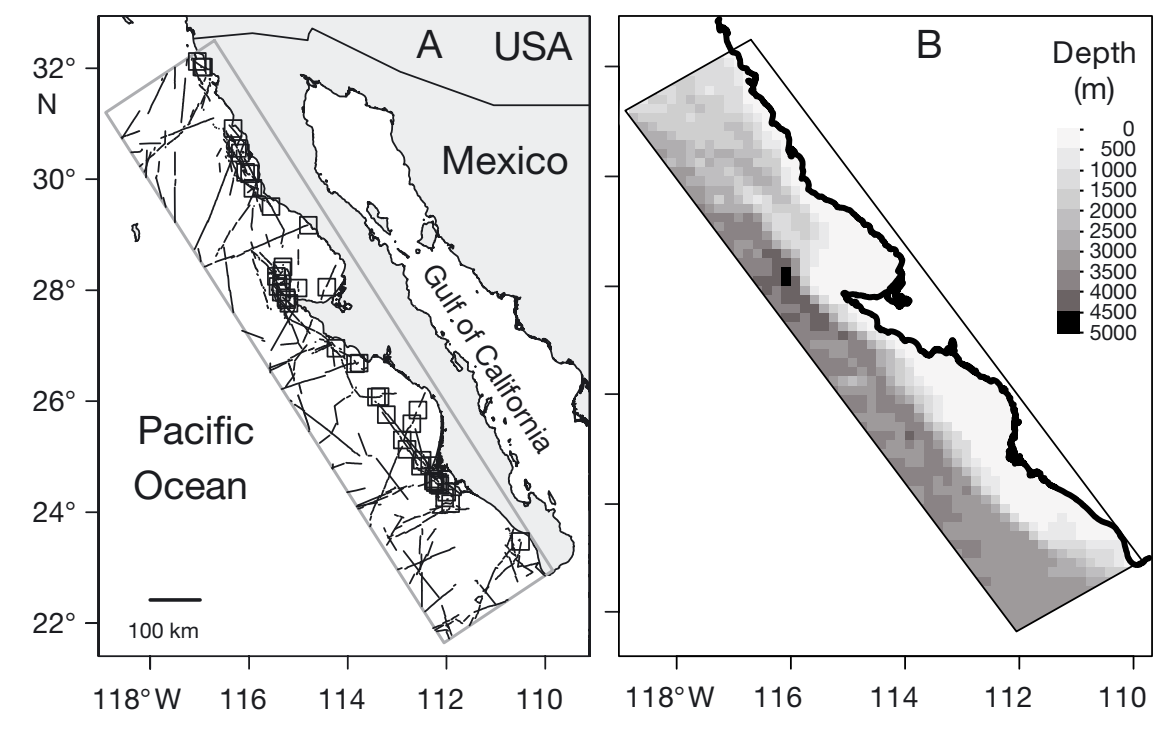

Fig. 1. Delphinus capensis. (A) Tracklines (thin black lines) and long-beaked common dolphin sightings (squares) off the peninsula of Baja California, Mexico, 1986 to 2006. The rectangle outlines the area within which data were considered for this analysis. (B) Grid of 992 cells within the study area, shaded by mean depth 
are given in Kinzey et al. (2000) and Gerrodette \& Forcada (2005).

For this analysis, we selected data within a rectangular area approximately $300 \mathrm{~km}$ from the coast (Fig. 1A). Approximately 87000 depths within this area were extracted from the NOAA database (www. ngdc.noaa.gov/mgg/gdas/gd_designagrid.html) on a 1 min ( 1 nautical mile) scale. We divided the study area into smaller subareas within which depth was reasonably uniform and could be represented by a single value. Subareas could be of arbitrary size and shape, but for convenience we used a grid of 992 rectangular cells, each $1 / 6$ of a degree $(\sim 18 \mathrm{~km})$ per side. The areas of the rectangular cells decreased slightly with latitude, but the mean area of non-boundary cells was $306 \mathrm{~km}^{2}$. There were about 90 depth values in each cell, with mean cell depths ranging up to nearly $5000 \mathrm{~m}$ (Fig. 1B).

Our analytical framework was a hierarchical Bayesian line-transect model, an extension of the basic model of Eguchi \& Gerrodette (2009). If $n$ objects are encountered in survey distance $L$, the density of objects $d$ is:

$$
d=\frac{n}{2 w L}
$$

Line-transect analysis estimates the 'effective' strip width $w$ on each side of the trackline, on the basis of the distribution of distances of detected objects from the trackline. For long-beaked common dolphins, the number of dolphin schools $n_{i}$ detected in each cell $i$ with non-zero effort depended on the actual density $d_{i}$ and the observation process summarized by $w_{i}$ and $L_{i}$. We assumed that the $n_{i}$ followed a Poisson distribution:

$$
n_{i} \sim \operatorname{Pois}\left(2 w_{i} L_{i} d_{i}\right)
$$

where survey distances $L_{i}$ were known but $w_{i}$ and $d_{i}$ were estimated. For $w_{i}$ we assumed that Beaufort sea state could affect the probability of detecting a school of dolphins, and modeled strip width as (Marques \& Buckland 2004, Gerrodette \& Forcada 2005):

$$
w_{i}=\exp \left(\alpha_{0}+\alpha_{1} c_{i}\right)
$$

where $C_{i}$ was Beaufort sea state in cell $i$ during the survey. Parameters $\alpha_{0}$ and $\alpha_{1}$ were estimated from the perpendicular distance $y_{j}$ and sea state $b_{j}$ for each sighting $j$ with a normal likelihood, with mean zero and variance $\left(\sigma^{2}\right)$, such that:

$$
\begin{gathered}
y_{j} \sim \mathcal{N}\left(0, \sigma_{j}^{2}\right) \\
\sigma_{j}=\exp \left(\alpha_{0}+\alpha_{1} b_{j}\right) \sqrt{2 / \pi}
\end{gathered}
$$

that is, a half-normal detection function with a seastate covariate ( $\mathcal{N}$ : normal distribution). We modeled the density of dolphin schools $d_{i}$ as a function of depth with linear, half-normal and hazard-rate functions, but report results only for the latter, which has the most flexible form of the three. The hazard-rate model was:

$$
d_{i}=\beta_{0}\left(1-\exp \left(-\left(z_{i} / \beta_{1}\right)^{\beta_{2}}\right)\right)
$$

where $z_{i}$ was the mean depth in cell $i$ as a positive value, and $\beta_{0}, \beta_{1}$ and $\beta_{2}$ were parameters to be estimated. To compute the density of animals, group size $s$ was estimated with a normal likelihood from the $n=$ $\Sigma n_{j}$ observed dolphin school sizes $g$,

$$
g_{j} \sim \mathcal{N}\left(s, \sigma_{s}^{2}\right)
$$

assuming a known variance $\sigma_{s}^{2}=\operatorname{var}(g) / n$.

The number of dolphins in each cell was $s d_{i} A_{i}$ where $A_{i}$ was the water area of cell $i$. The cumulative abundance of dolphins occurring within an area shallower than depth $k$ was:

$$
N(k)=\sum s d_{i} A_{i} \text { for cells } i \text { with } z_{i}<k
$$

and the cumulative percentage of abundance occurring within an area shallower than depth $k$ was:

$$
P(k)=100 N(k) / N_{\text {tot }}
$$

where $N_{\text {tot }}$ was the sum of the number of animals in all cells in the study area.

We used Markov Chain Monte Carlo methods, specifically the Gibbs sampler implemented in the BRugs package in $\mathrm{R}$ ( $\mathrm{R}$ Development Core Team 2009), to estimate basic parameters $\alpha_{0}, \alpha_{1}, \beta_{0}, \beta_{1}, \beta_{2}$ and $s$, as well as derived parameters $N(k)$ and $P(k)$. We assumed flat prior distributions for all basic parameters. BUGS code (Lunn et al. 2000) for the model is given in the supplement at www.int-res.com/ articles/suppl/n015p159_supp/. After a burn-in phase of 20000 samples, we ran 1000000 steps, retaining every tenth value, for a posterior sample of 100000 values for inference. Convergence was checked by obtaining similar posterior distributions with different initial values. We further checked our results by obtaining similar posterior distributions with nonMarkov Chain Monte Carlo methods (uniform sampling across a 6 -dimensional array), and by obtaining point estimates for the detection function and total abundance with Distance software (Thomas et al. 2010); these estimates were similar to the medians of the posterior distributions.

\section{RESULTS}

There was a total of $8545 \mathrm{~km}$ of survey effort within the study area, with non-zero effort in 531 of the 992 cells. Survey effort distances in individual cells 
ranged from 0 to $65 \mathrm{~km}$, with a predominance of lower values (Fig. 2A). Effort-weighted mean Beaufort sea state conditions in each cell ranged from 0 to 5, with a predominance of higher values (Fig. 2B).

There was a total of 44 sightings of long-beaked common dolphin Delphinus capensis schools in 36 cells, with group sizes ranging from 1 to 6393 . Mean group size was $512(\mathrm{SE}=154)$. The frequency of perpendicular distances from the trackline of the sightings declined with distance (Fig. 3A). Depths within the study area were bimodally distributed between 0 and $5000 \mathrm{~m}$ (Fig. 3B, dashed lines), and tracklines sampled all depths (Fig. 3B, solid lines). Sightings occurred in a restricted fraction of these depths, mainly $<250 \mathrm{~m}$ (Fig. 3B, gray bars). Of the 44 sightings, 6 occurred deeper than $500 \mathrm{~m}$, and only one occurred deeper than $1000 \mathrm{~m}$.

Long-beaked common dolphins were estimated to occur at a mean density of about 2 animals $\mathrm{km}^{-2}$ in shallow water (Fig. 4A). The 0.1 and 0.9 quantiles (i.e. a central $80 \%$ credibility interval) of the posterior distribution at this depth were 1.6 and $2.8 \mathrm{~km}^{-2}$, respectively. The hazard-rate model predicted that density was constant from about 0 to $200 \mathrm{~m}$, and then decreased with depth, falling to a mean density of $0.3 \mathrm{~km}^{-2}$ by $1000 \mathrm{~m}$, and $<0.03 \mathrm{~km}^{-2}$ by $1500 \mathrm{~m}$. Based on this function, the highest densities of animals occurred on the continental shelf (Fig. 4B). A posterior distribution of density was calculated at each of the 27000 depths in the study area; the median value of each distribution is plotted in Fig. 4B.

Cumulative abundance $N(k)$ and percentage of abundance $P(k)$ both rose rapidly at depths $<200 \mathrm{~m}$ and then approached an asymptote (Fig. 5). There was less uncertainty about the percentage of a population included at a given depth than about the absolute number (shaded areas in Fig. 5).

Setting the boundary of a protected area at $360 \mathrm{~m}$ would meet the first management goal of including 100000 animals with a probability of 0.9 (Fig. 5A, dashed lines). Setting the boundary at
$160 \mathrm{~m}$ could also include 100000 animals, but only with a probability of 0.5 (the median, Fig. 5A, vertical dotted line).

Setting the boundary at $210 \mathrm{~m}$ would meet the second management goal of including $60 \%$ of the population within the area with a probability of 0.9 (Fig. 5B, dashed lines). Setting the boundary at $170 \mathrm{~m}$ would include $60 \%$ of the population with a probability of 0.5 (Fig. 5B, vertical dotted line).

Because these depth boundaries are on or near the continental slope, the areas within the depths are not very different along much of the Baja California Pacific coast (Fig. 6). The areas between the coastline and the 160,170, 210 and $360 \mathrm{~m}$ isobaths within the study area were $46.7 \times 10^{3}, 47.7 \times 10^{3}, 51.4 \times 10^{3}$ and $61.3 \times 10^{3} \mathrm{~km}^{2}$, respectively.
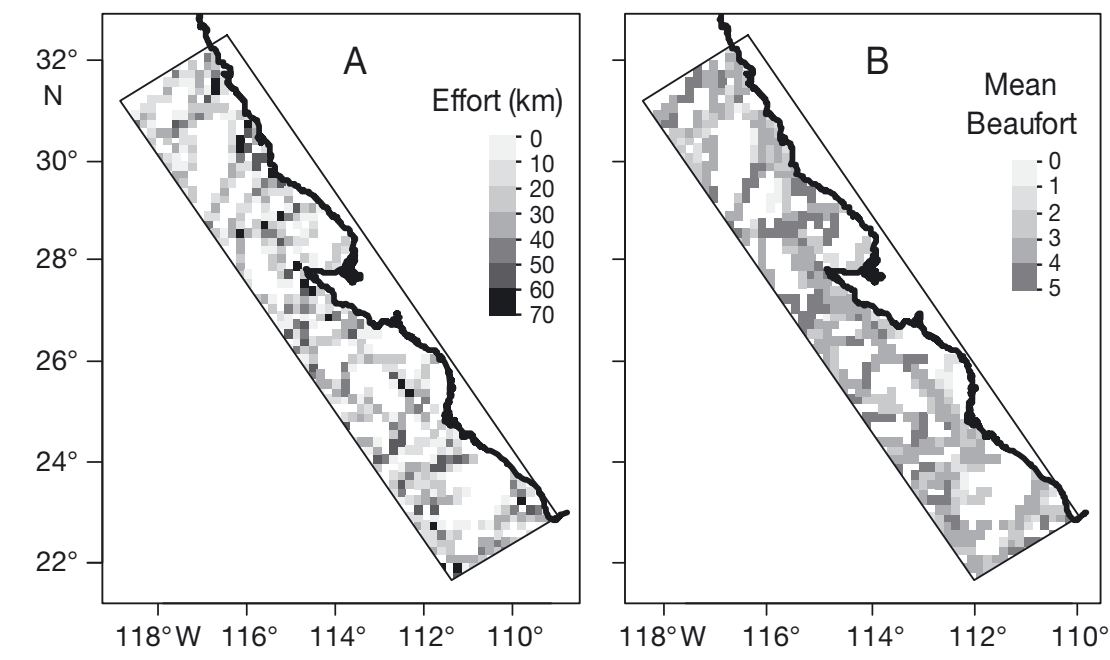

Fig. 2. Delphinus capensis. (A) Survey effort in each cell. (B) Effort-weighted mean Beaufort sea state conditions at the time of the survey in each cell. Blank cells had no survey effort
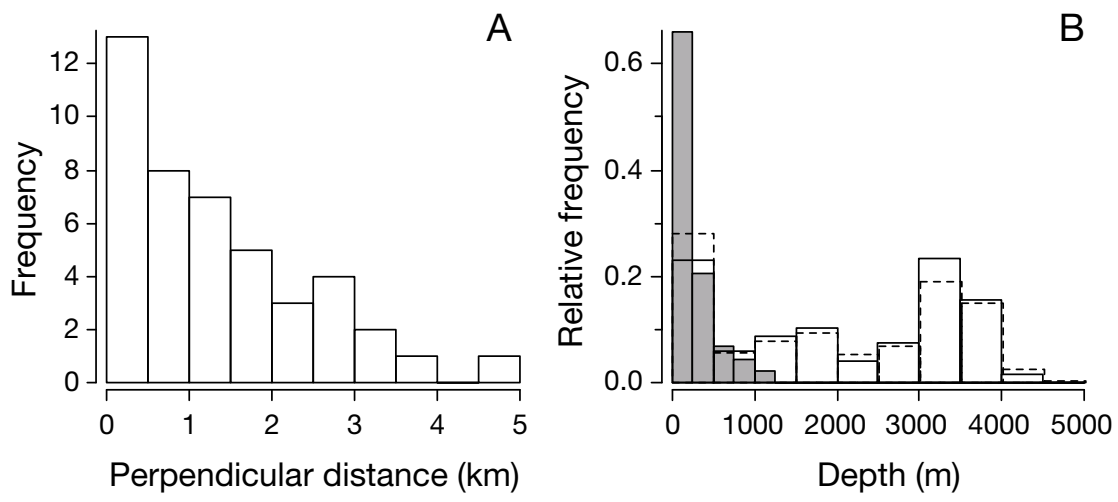

Fig. 3. Delphinus capensis. (A) Frequency of perpendicular distances of sightings from the trackline. (B) Relative frequencies of depths of cells with sightings (gray bars), cells with survey effort (solid lines), and all cells in the study area (dashed lines) 

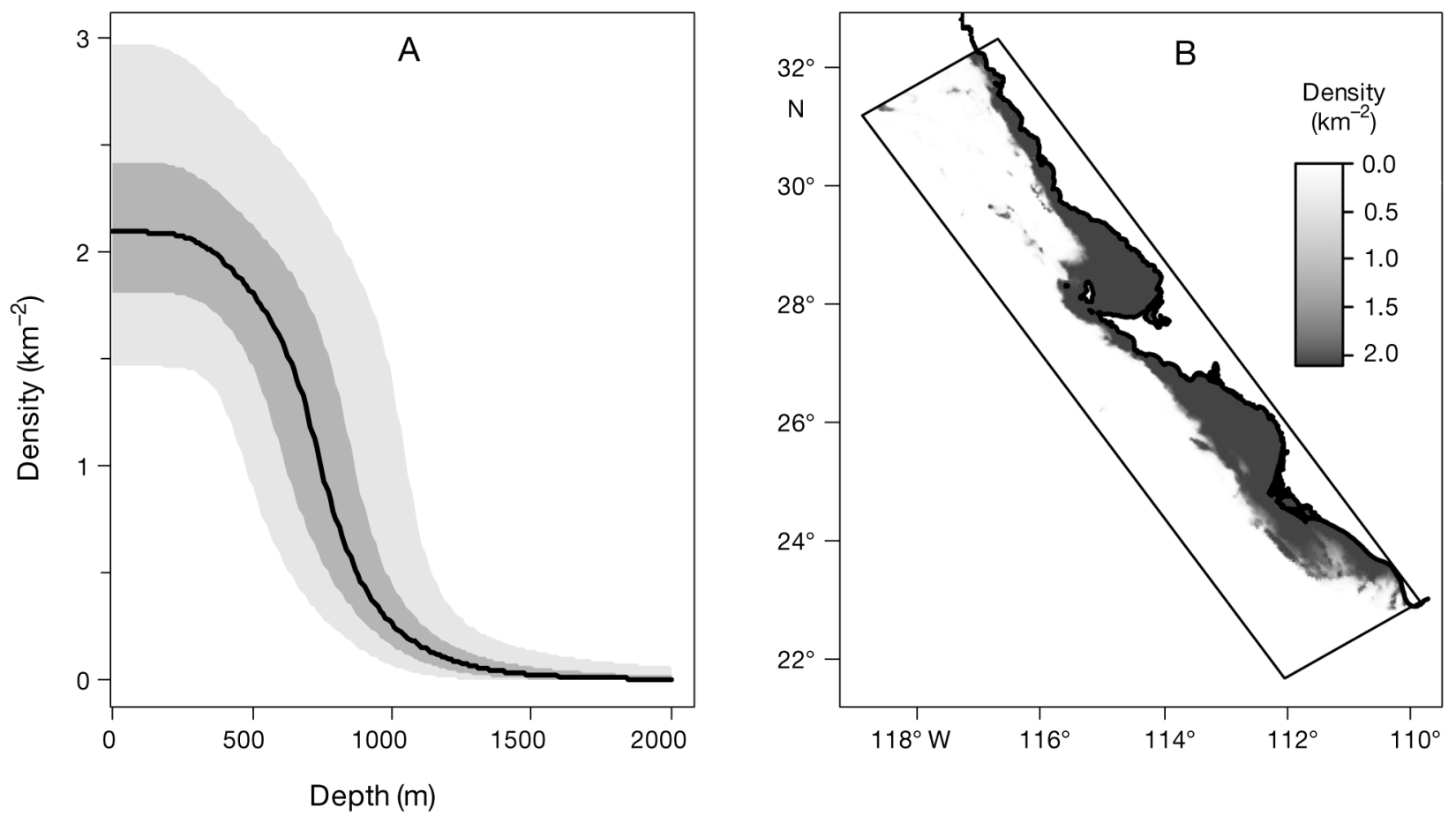

Fig. 4. Delphinus capensis. (A) Animal density as a hazard-rate function of depth. The line connects the medians; dark gray, central $50 \%$ and light gray, central $90 \%$ of the posterior distributions at each depth. (B) Spatial distribution of animal density based on depth at a 1 min scale, shaded by median posterior animal density

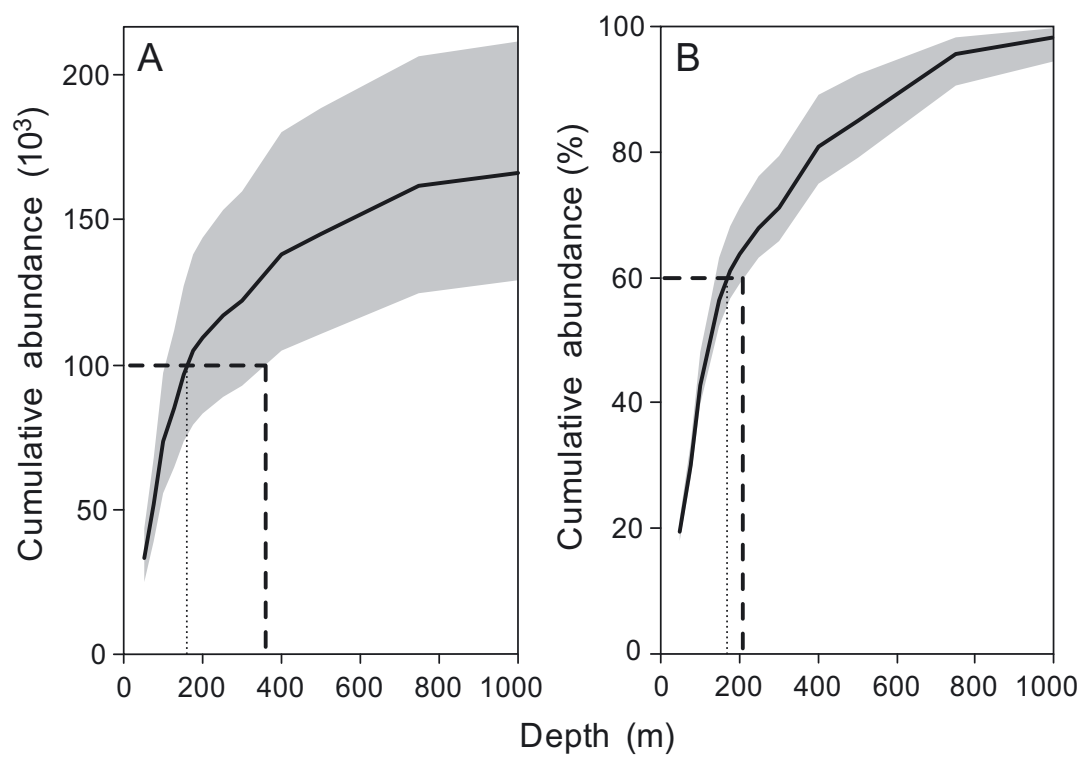

Fig. 5. Delphinus capensis. (A) Cumulative abundance by depth. (B) Cumulative percentage of abundance by depth. Solid lines connect the medians, and the shaded areas are bounded by the 0.1 and 0.9 quantiles of the posterior distributions. Horizontal dashed lines correspond to management targets of (A) protecting 100000 dolphins or (B) protecting $60 \%$ of the population. Vertical dashed lines indicate the depths corresponding to a precautionary policy of achieving these targets with a probability of 0.9 . Vertical dotted lines indicate the depths corresponding to a less precautionary policy of achieving these targets with a probability of 0.5

\section{DISCUSSION}

A frequent goal of a protected area, such as a reserve, park or sanctuary, is to protect the critical habitat of a species. If 'critical' is defined in sufficiently quantitative terms, data can be used to determine whether a proposed area will meet or has met the management goal. For effective management, uncertainty should also be recognized and considered. If policy makers specify the level of precaution, scientists can estimate parameters consistent with those policy goals. Here we assumed that a quantitative management goal, and a desired probability of meeting that goal, had been articulated for a potential protected area of a coastal cetacean, the long-beaked common dolphin Delphinus capensis.

A hierarchical Bayesian line-transect habitat model estimated dolphin density as a hazard-rate function of depth (Fig. 4A). The depth which would represent a management goal 


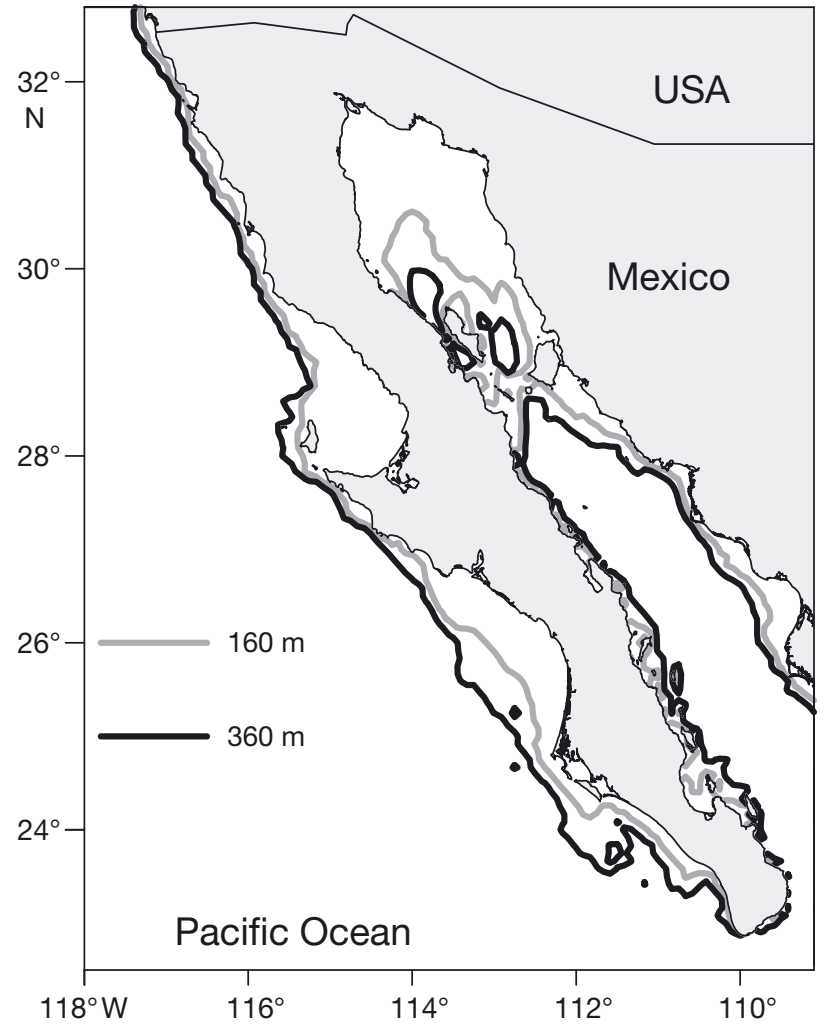

Fig. 6. Locations of 160 and $360 \mathrm{~m}$ isobaths around the peninsula of Baja California, Mexico

of including 100000 dolphins in the protected area with a probability of 0.5 was $160 \mathrm{~m}$ (Fig. 5A). For many purposes this is a reasonable estimate, but it is not a precautionary estimate. There is a $50 \%$ probability that there are fewer than 100000 dolphins in waters shallower than $160 \mathrm{~m}$. In other words, there is only a 50:50 chance that the management goal would be met. The 'best' estimate does not lead to the best management with respect to conserving the species (Taylor \& Wade 2000).

A precautionary approach achieves the management goal with a high probability. We postulated that the level of precaution had been set, as a matter of policy, at 0.9 . For the management goal of including 100000 dolphins to be met with this higher probability, the boundary of the protected area would have to be $360 \mathrm{~m}$, on the basis of the habitat model (Fig. 5A). In this case, there was a considerable difference in depth (160 vs. $360 \mathrm{~m}$ ) between the non-precautionary and precautionary boundary of the protected area.

For a second management goal of including at least $60 \%$ of the population, there was a smaller difference between the depth of the precautionary bound- ary $(210 \mathrm{~m})$ and the non-precautionary one $(170 \mathrm{~m}$; Fig. 5B). The difference was smaller because there was less uncertainty about the cumulative percentage of the population contained within a given depth than about the absolute number of animals within the same depth.

We emphasize that the design of a protected area for long-beaked common dolphins was a hypothetical case study. Delphinus capensis is not endangered, nor has it been shown that the species is declining or in need of special protection. We chose the species for the case study because transect data were available and the distribution of $D$. capensis could be reasonably modeled by depth alone. Furthermore, the design of an actual reserve would consider social, political, economic and logistical factors, as well as biological data. Several programs are available to help optimize reserve design, such as Marxan (www.uq.edu.au/marxan), MarineMap (http://marinemap.org/) and Zonation (www.helsinki. fi/science/metapop/Research/Project_spatial4.htm).

To infer cetacean habitat use from line-transect data, the separate components of a density estimator, such as sighting rate, group density, group size and effective strip width, may be modeled as functions of environmental variables, then combined to estimate density at small spatial scales (Cañadas \& Hammond 2006, Ferguson et al. 2006, Gómez de Segura et al. 2007, Cañadas \& Hammond 2008, Becker et al. in press, Forney et al. in press). Estimation of density and habitat relationships may also be combined in a single analysis (Hedley et al. 2004, Royle et al. 2004, Johnson et al. 2010, Niemi \& Fernández 2010). Inference about population processes is improved when combined with an observation model into a single likelihood framework (Goodman 2004, Buckland et al. 2007, Royle \& Dorazio 2008).

Fortunately for cetaceans, factors which are related to abundance, such as temperature, primary productivity, or depth in this case, can often be separated from factors that affect detection probability, such as number of observers, height of observation, or sea state in this case. We assumed that depth had little or no effect on the probability of detection of dolphins and that sea state at the time of the survey had little or no effect on the abundance of dolphins. The analysis attempted to account for the imperfect detection of animals in order to relate the true, but unobserved, number of animals to habitat factors. Bayesian methods provide a coherent framework for quantifying uncertainty (Clark 2005, Royle \& Dorazio 2006, Cressie et al. 2009). Furthermore, because a Bayesian analysis expresses uncertainty in terms of 
probabilities, results can be used directly in decisionmaking (Punt \& Hilborn 1997, Goodman 2009), such as setting the boundary of a protected area.

The habitat model in the present study, while adequate to illustrate the importance of accounting for uncertainty in the design of a protected area, was relatively simple. More flexible models with additional habitat predictor variables should be considered for comprehensive estimation of Delphinus capensis habitat. Cañadas \& Hammond (2008), for example, found that abundance of $D$. delphis in the Mediterranean Sea off southern Spain tended to be bimodal with depth, a pattern that would not be modeled by the hazard-rate function used here. The probability of detecting dolphin schools may depend on additional variables, particularly group size (Gerrodette \& Forcada 2005). The Poisson distribution assumed that the numbers of dolphin schools detected per cell were independent after adjusting for survey effort, sea state and depth. If the density of schools depended on other factors - patches of prey across several cells, for example-the numbers of sightings could be spatially correlated.

Spatial management based on sea-surface temperature or other dynamic habitat variables without fixed geographic boundaries is natural and ecologically sensible in the ocean (Norse \& Crowder 2005). Habitat variables which are not geographically fixed can be modeled, but pose challenges for implementation and enforcement of protected areas based on such variables. Nevertheless, fishing restrictions based on dynamic habitat conditions have been implemented to reduce bycatch of loggerhead sea turtles Caretta caretta. Along the coast of southern California, USA, fishing with drift gillnets is prohibited from June 1 to August 31 if El Niño conditions exist or are predicted (Federal Register 2002, 2007). Around the waters of Hawaii, fishers are warned of higher risk of interaction with turtles in areas within a certain sea-surface temperature range (Howell et al. 2008). As more knowledge about the interactions between protected species and environment accumulates, habitat-based management rules based on dynamic variables may become more prevalent, but it is important to take the uncertainty about the estimated habitat relationship into account.

Acknowledgements. We thank F. Archer for assistance with $\mathrm{R}$ coding in BRugs, and T. J. Moore for calculating areas enclosed by different isobaths. S. Chivers, J. Butler, R. Williams and 1 anonymous reviewer provided comments which improved the manuscript. Line-transect data were collected under research permits issued by the Government of Mexico to the Southwest Fisheries Science Center, NMFS, NOAA.

\section{LITERATURE CITED}

Becker EA, Foley DG, Forney KA, Barlow J, Redfern JV, Gentemann CL (in press) Forecasting cetacean abundance patterns to enhance management decisions. Endang Species Res doi:10.3354/esr00390

> Buckland ST, Newman KB, Fernández C, Thomas L, Harwood J (2007) Embedding population dynamics models in inference. Stat Sci 22:44-58

Cañadas A, Hammond PS (2006) Model-based abundance estimates for bottlenose dolphins off southern Spain: implications for conservation and management. J Cetacean Res Manag 8:13-27

Cañadas A, Hammond PS (2008) Abundance and habitat preferences of the short-beaked common dolphin Delphinus delphis in the southwestern Mediterranean: implications for conservation. Endang Species Res 4:309-331

Clark JS (2005) Why environmental scientists are becoming Bayesians. Ecol Lett 8:2-14

Cressie N, Calder CA, Clark JS, Ver Hoef JM, Wikle C (2009) Accounting for uncertainty in ecological analysis: the strengths and limitations of hierarchical statistical modeling. Ecol Appl 19:553-570

Eguchi T, Gerrodette T (2009) A Bayesian approach to linetransect analysis for estimating abundance. Ecol Model 220:1620-1630

Federal Register (2002) Taking of threatened or endangered species incidental to commercial fishing operations. 50 CFR Part 223, RIN 0648-AQ13. Fed Regist 67: 78388-78392

Federal Register (2007) Fisheries off west coast states: highly migratory species fisheries. 50 CFR Parts 224 and 660. RIN 0648-AS89. Fed Regist 72:4225-4226

Ferguson MC, Barlow J, Reilly SB, Gerrodette T (2006) Predicting Cuvier's (Ziphius cavirostris) and Mesoplodon beaked whale population density from habitat characteristics in the eastern tropical Pacific Ocean. J Cetacean Res Manag 7:287-299

Forney KA, Ferguson MC, Becker EA, Fiedler PC and others (in press) Habitat-based spatial models of cetacean density in the eastern Pacific Ocean. Endang Species Res doi:10.3354/esr00393

> Gerrodette T, DeMaster DP (1990) Quantitative determination of optimum sustainable population level. Mar Mamm Sci 6:1-16

> Gerrodette T, Forcada J (2005) Non-recovery of two spotted and spinner dolphin populations in the eastern tropical Pacific Ocean. Mar Ecol Prog Ser 291:1-21

> Gómez de Segura A, Hammond PS, Cañadas A, Raga JA (2007) Comparing cetacean abundance estimates derived from spatial models and design-based line-transect methods. Mar Ecol Prog Ser 329:289-299

$>$ Goodman D (2004) Methods for joint inference from multiple data sources for improved estimates of population size and survival rates. Mar Mamm Sci 20:401-423

Goodman D (2009) The future of fisheries science: merging stock assessment with risk assessment, for better fisheries management. In: Beamish RJ, Rothschild BJ (eds) The future of fisheries science in North America. Springer Science, Dordrecht, p 535-564 
Hedley SL, Buckland ST, Borchers DL (2004) Spatial distance sampling models. In: Buckland ST, Anderson DR, Burnham KP, Laake JL, Borchers DL, Thomas L (eds) Advanced distance sampling: estimating abundance of biological populations. Oxford University Press, Oxford, p 48-70

Heyning JE, Perrin WF (1994) Evidence for two species of common dolphins (genus Delphinus) from the eastern North Pacific. Nat Hist Mus Los Ang Cty Contrib Sci 442:1-35

Howell EA, Kobayashi DR, Parker DM, Balazs GH, Polovina JJ (2008) TurtleWatch: a tool to aid in the bycatch reduction of loggerhead turtles Caretta caretta in the Hawaiibased pelagic longline fishery. Endang Species Res 5: 267-278

Johnson DS, Laake JL, Ver Hoef JM (2010) A model-based approach for making ecological inference from distance sampling data. Biometrics 66:310-318

Kinzey D, Olson P, Gerrodette T (2000) Marine mammal data collection procedures on research ship line-transect surveys by the Southwest Fisheries Science Center. Admin Rep LJ-00-08, SWFSC, La Jolla, CA

Ludwig D, Hilborn R, Walters C (1993) Uncertainty, resource exploitation, and conservation: lessons from history. Science 260:17-36

Lunn DJ, Thomas A, Best N, Spiegelhalter D (2000) WinBUGS - a Bayesian modelling framework: concepts, structure, and extensibility. Stat Comput 10:325-337

Mangel M, Talbot LM, Meffe GK, Agardy MT and others (1996) Principles for the conservation of wild living resources. Ecol Appl 6:338-362

Marques FFC, Buckland ST (2004) Covariate models for the detection function. In: Buckland ST, Anderson DR, Burnham KP, Laake JL, Borchers DL, Thomas L (eds) Advanced distance sampling: estimating abundance of biological populations. Oxford University Press, Oxford, p 31-47

Niemi A, Fernández C (2010) Bayesian spatial point process modeling of line transect data. J Agric Biol Environ Stat 15:327-345

Editorial responsibility: Kristin Laidre,

Seattle, Washington, USA
Norse EA, Crowder LB (2005) Marine conservation biology: the science of maintaining the sea's biodiversity. Island Press, Washington, DC

Punt AE, Hilborn R (1997) Fisheries stock assessment and decision analysis; the Bayesian approach. Rev Fish Biol Fish 7:35-63

R Development Core Team (2009) R: a language and environment for statistical computing. R Foundation for Statistical Computing, Vienna

Rice DW (1998) Marine mammals of the world: systematics and distribution. The Society for Marine Mammalogy, Lawrence, KS

> Rosel PE, Dizon AE, Heyning JE (1994) Genetic analysis of sympatric morphotypes of common dolphins (genus Delphinus). Mar Biol 119:159-167

Royle JA, Dorazio RM (2006) Hierarchical models of animal abundance and occurrence. J Agric Biol Environ Stat 11: 249-263

Royle JA, Dorazio RM (2008) Hierarchical modeling and inference in ecology: the analysis of data from populations, metapopulations and communities. Elsevier, London

Royle JA, Dawson DK, Bates S (2004) Modeling abundance effects in distance sampling. Ecology 85:1591-1597

Taylor BL, Wade PR (2000) 'Best' abundance estimates and best management: why they are not the same. In: Ferson S, Burgman M (eds) Quantitative methods for conservation biology. Springer, New York, NY, p 96-108

Taylor BL, Wade PR, DeMaster DP, Barlow J (2000) Incorporating uncertainty into management models for marine mammals. Conserv Biol 14:1243-1252

> Thomas L, Buckland ST, Rexstad EA, Laake JL and others (2010) Distance software: design and analysis of distance sampling surveys for estimating population size. J Appl Ecol 47:5-14

Wade PR (1998) Calculating limits to the allowable humancaused mortality of cetaceans and pinnipeds. Mar Mamm Sci 14:1-37

Submitted: January 16, 2011; Accepted: July 18, 2011

Proofs received from author(s): October 4, 2011 